\title{
Rainfall Estimation Using Specific Differential Phase for the First Operational Polarimetric Radar in Korea
}

\author{
Cheol-Hwan You, ${ }^{1}$ Dong-In Lee, ${ }^{2}$ and Mi-Young Kang ${ }^{1}$ \\ ${ }^{1}$ Hydrospheric Atmospheric Research Center, Nagoya University, Furo-cho, Chikusa-ku, Nagoya 464-8601, Japan \\ ${ }^{2}$ Department of Environmental Atmospheric Sciences, Pukyong National University, Yongso-ro, Nam-gu, \\ Busan 608-737, Republic of Korea \\ Correspondence should be addressed to Dong-In Lee; leedi@pknu.ac.kr
}

Received 25 November 2013; Revised 14 January 2014; Accepted 15 January 2014; Published 24 February 2014

Academic Editor: Hiroyuki Hashiguchi

Copyright (c) 2014 Cheol-Hwan You et al. This is an open access article distributed under the Creative Commons Attribution License, which permits unrestricted use, distribution, and reproduction in any medium, provided the original work is properly cited.

\begin{abstract}
To assess the performance of rainfall estimation using specific differential phase observed by Bislsan radar, the first polarimetric radar in Korea, three rainfall cases occurring in 2011 were selected, each caused by different conditions: the first is the Changma front and typhoon, the second is only the Changma front, and the third is only a typhoon. For quantitative use of specific differential phase $\left(K_{\mathrm{DP}}\right)$, a data quality algorithm was developed for differential phase shift $\left(\Phi_{\mathrm{DP}}\right)$, composed of two steps; the first involves removal of scattered noise and the second is unfolding of $\Phi_{\mathrm{Dp}}$. This order of the algorithm is necessary so as not to remove unfolded areas, which are the real meteorological target. All noise was removed and the folded $\Phi_{\mathrm{DP}}$ were unfolded successfully for this study. $R\left(K_{\mathrm{DP}}\right)$ relations for S-band radar were calculated for 84,754 samples of observed drop size distribution (DSD) using different drop shape assumptions. The relation for the Bringi drop shape showed the best statistics: 0.28 for normalized error, and $6.7 \mathrm{~mm}$ for root mean square error for rainfall heavier than $10 \mathrm{~mm} \mathrm{~h}^{-1}$. Because the drop shape assumption affects the accuracy of rainfall estimation differently for different rainfall types, such characteristics should be taken into account to estimate rainfall more accurately using polarimetric variables.
\end{abstract}

\section{Introduction}

Weather radar is a very useful remote sensing tool for estimating rainfall amount because of its high spatial and time resolution compared with other instruments. Measurements of rainfall by radar are generally based on the relationship between the reflectivity factor $(Z)$ and rain rate $(R)$, termed the $Z-R$ relation (hereafter $R(Z)$ ). Experimentally measured DSDs have been extensively used to calculate both radar reflectivity and rain rate [1]. It can be shown that there is no unique global $R(Z)$ relation because DSDs can vary from storm to storm and within the storm itself [2]. Many researchers have noted that radar rainfall estimation is contaminated by a number of uncertainties such as hardware calibration, partial beam filling, rain attenuation, bright band, and nonweather echoes $[3,4]$. Several studies in Korea have calculated the $R(Z)$ relationship using disdrometer data for different rainfall types and calirated rainfall amount with rain gages for operational Doppler weather radars [5-7].
Numerous studies have investigated the implementation of polarimetric radar for operational use. A particle identification algorithm has been developed to improve data quality control and rainfall estimates by distinguishing nonmeteorological artifacts such as anomalous propagation, birds, insects, second-trip echo, and melting-layer detection [810]. The improvement of quantitative precipitation estimation (QPE) accuracy is one of the major advantages of polarimetric radar [11-15]. Cifelli et al. [16] recently compared the performance of two rainfall algorithms in a high plains environment: the CSU-HIDRO (Colorado State UniversityHydrometeor IDentification of Rainfall) and one based on the JPOLE (Joint Polarization Experiment). Based on these theoretical and other experimental studies, many countries are replacing or modifying their radars to provide polarimetric radar for operational use. The specific differential phase is a very useful parameter for rainfall estimation because it is not susceptible to radar calibration, beam attenuation, or beam 


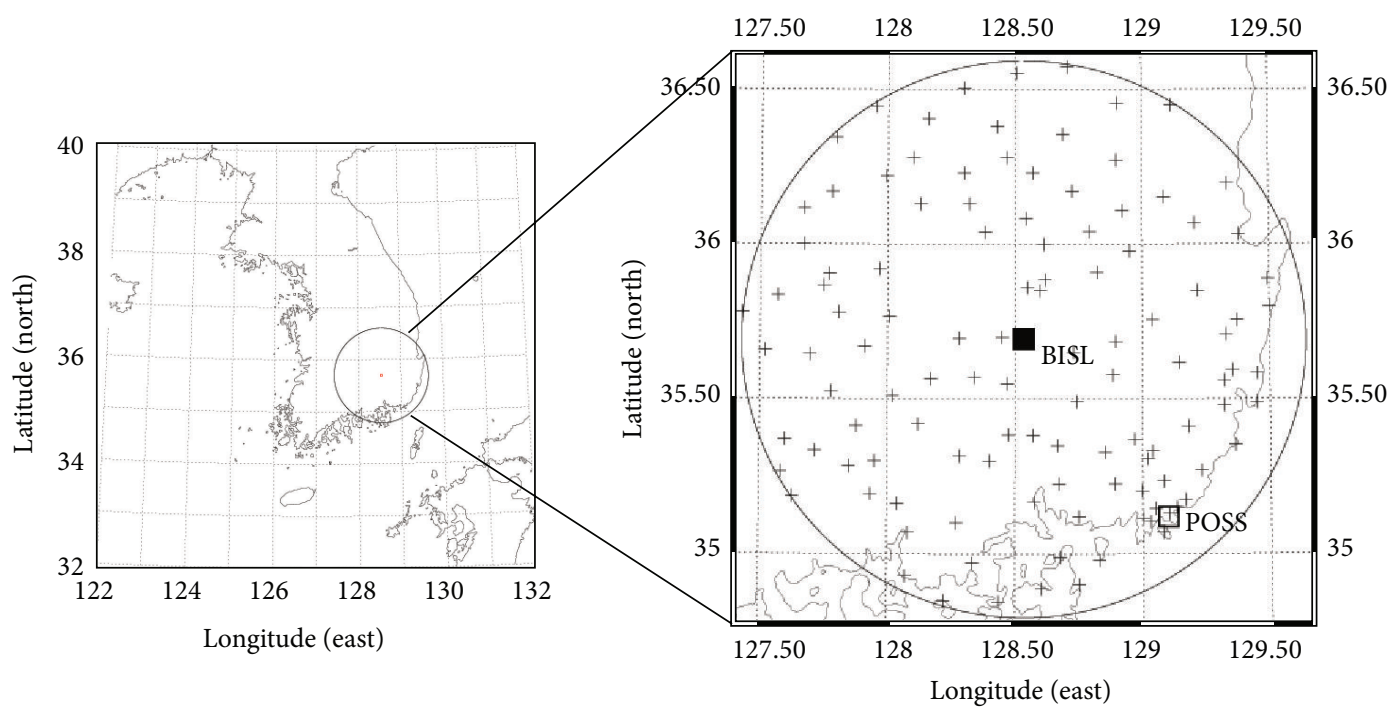

(a)

(b)

FIGURE 1: The location of the Bislsan radar (solid rectangle), the POSS disdrometer (open rectangle), and rain gages (plus signs) distributed within the area of radar coverage (100 km radius).

blockage. It is also closely related to rain intensity, even in the presence of dry, tumbling hail [17, 18].

Three major agencies use radars to monitor and forecast severe weather and flash floods operationally in Korea: the Ministry of National Defense (MND), the Ministry of Land, Infrastructure and Transportation (MOLIT), and the Korea Meteorological Administration (KMA). MOLIT installed polarimetric radars for the first time in Korea in 2009 and 2012. The successful implementation of these radars for operational use requires studies of rainfall estimation, hydrometeor classification, and DSD retrieval. However, there are few studies on these polarimetric related issues, other than for deriving relationships using long period disdrometer data, assessing each relation after applying a very simple quality control for differential phase shift [19]. The accuracy of rainfall estimation using $R\left(K_{\mathrm{DP}}\right)$ was found to be worse than that of $R\left(Z, Z_{D R}\right)$.

This paper discusses how the accuracy of rainfall estimation can be improved using specific differential phase measured by the first polarimetric radar installed in Korea. Section 2 describes the data used in this study, the calculation of the relationship between specific differential phase and rain rate, the data quality control of differential phase shift, and the statistical validation. Section 3 gives results for rainfall estimation using specific differential phase and describes the effect of quality control of differential phase shift including the unfolding algorithm. Finally, Section 4 summarizes the results and provides some concluding remarks.

\section{Data and Methodology}

2.1. Rain Gage and Radar Dataset. The rainfall data from rain gages operated by the KMA were used to evaluate the accuracy of radar rainfall. Rain gages located at distances of $5 \mathrm{~km}$ to $100 \mathrm{~km}$ from the radar are included in the analysis. Figure 1 shows the location of all instruments used in this study. The circle represents the radar coverage, the solid rectangle is the center of the Bislsan radar, plus signs show the distributed rain gages within the radar coverage, and the open rectangle is the position of a POSS (Precipitation Occurrence Sensor System) disdrometer, which was located around $82 \mathrm{~km}$ from the radar. The POSS disdrometer will be described in more detail in the next section.

Radar data were collected by the Bislsan S-band polarimetric radar, which was installed and operated by MOLIT in Korea from 2009. The transmitted peak power is $750 \mathrm{~kW}$, beam width is $0.95^{\circ}$, and frequency is about $2.8 \mathrm{GHz}$. Horizontal and vertical reflectivity $\left(Z_{h}, Z_{v}\right)$, radial velocity (VR), spectrum width (SW), differential reflectivity $\left(Z_{\mathrm{DR}}\right)$, differential phase shift $\left(\Phi_{\mathrm{DP}}\right)$, specific differential phase $\left(K_{\mathrm{DP}}\right)$, and cross correlation coefficient $\left(\rho_{h v}\right)$ are estimated with a gate size of $0.125 \mathrm{~km}$. The scan strategy is composed of 6 elevation angles with a 2.5-minute update interval. The values of $\Phi_{\mathrm{DP}}$ and $K_{\mathrm{DP}}$ for $0.5^{\circ}$ elevation angle were extracted from the volume data every 2.5 minutes.

The quality control algorithm consists of a $\Phi_{\mathrm{DP}}$ unfolding stage and a noise removal stage. It is applied to improve rainfall estimates. The maximum observable value of $\Phi_{\mathrm{DP}}$ is $180^{\circ}$ for the Bislsan radar in 2011 . If the real $\Phi_{\mathrm{DP}}$ exceeds this value in the case of heavy rainfall, $\Phi_{\mathrm{DP}}$ may be folded (aliased) and should be unfolded for quantitative use. The procedure to unfold $\Phi_{\mathrm{DP}}$ is as follows.

(1) Check for folding by comparing the difference between the current gate value of $\Phi_{\mathrm{DP}}$ and the median of $\Phi_{\mathrm{DP}}$ for the previous 24 gates.

(2) The gage is designated as a folded gate if the difference satisfies the conditions shown in Figure 2.

(3) If it is folded, add $180^{\circ}$ to the folded value.

Noise removal is performed after unfolding as follows:

(1) calculation of standard deviation of $\Phi_{\mathrm{DP}}$ using 9 gates centered on the target gate, 


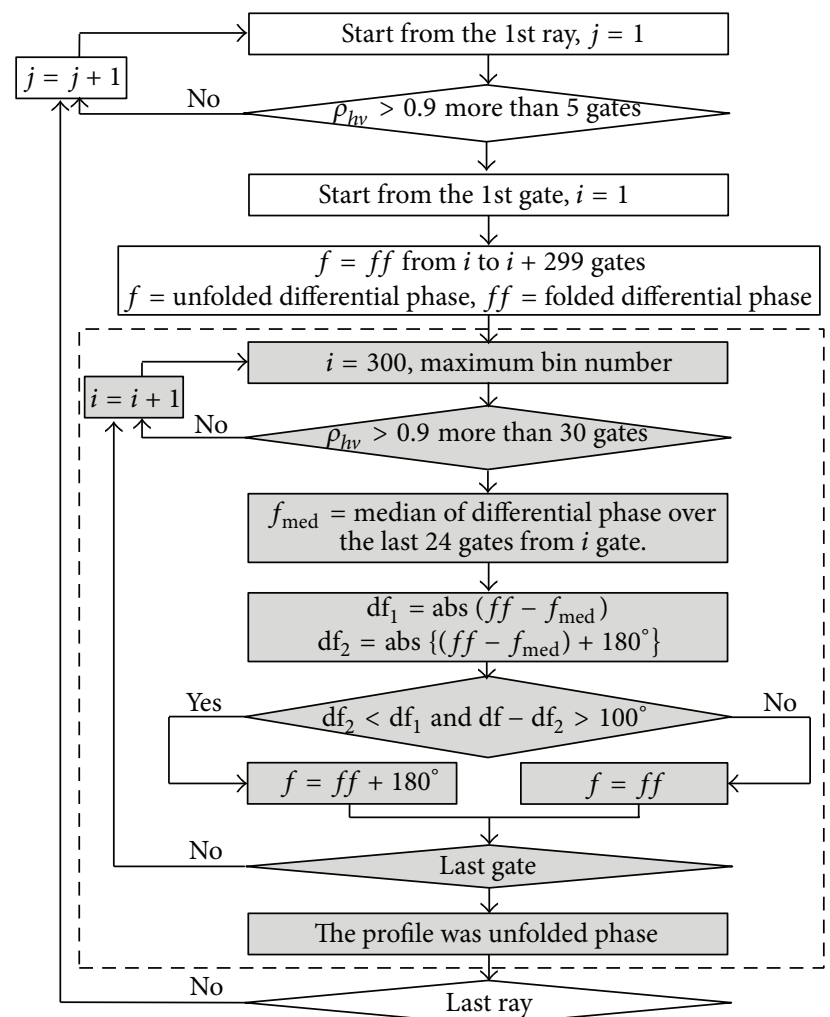

FIGURE 2: Flowchart of differential phase shift-unfolding algorithm.

(2) remove gate as noise if the standard deviation of $\Phi_{\mathrm{DP}}$ at the gate is more than 15 degrees,

(3) remove remaining noise by checking the number of missing gates in the 25 neighbor gates,

(4) use the average value of the 9 neighbor gates to replace the removed gate value.

$K_{\mathrm{DP}}$ is calculated from the slope of 9 and 25 gates of quality-controlled $\Phi_{\mathrm{DP}}$. If a reflectivity is higher (lower) than $40 \mathrm{dBZ}$, it is lightly (heavily) filtered. These $K_{\mathrm{DP}}$ are used to calculate rainfall amount. Figures 2 and 3 show the details of the $\Phi_{\mathrm{DP}}$ unfolding algorithm and noise removal procedure.

2.2. Calculation of $R\left(K_{D P}\right)$ and Validation. Relations for converting radar variables into rain rate are required because radar does not observe the rainfall directly. In order to calculate these relations, disdrometer data, which can measure the DSDs, are needed. A POSS is a low power, continuous wave, $\mathrm{X}$-band, bistatic system; here the transmitter and receiver are housed separately and mounted on a frame $45 \mathrm{~cm}$ apart [20].

One-minute DSDs obtained from March 2001 to September 2004 were processed to remove unreliable data, as shown in You et al. [19]. After quality control, there were 84,574 DSD samples available for calculating the relationships. Most of the data are distributed over a wide range with a maximum rain rate of about $199 \mathrm{~mm} \mathrm{~h}^{-1}$ (Figure 4).

$K_{\mathrm{DP}}$ was calculated for this study using T-matrix scattering techniques derived by Waterman [21] and later developed

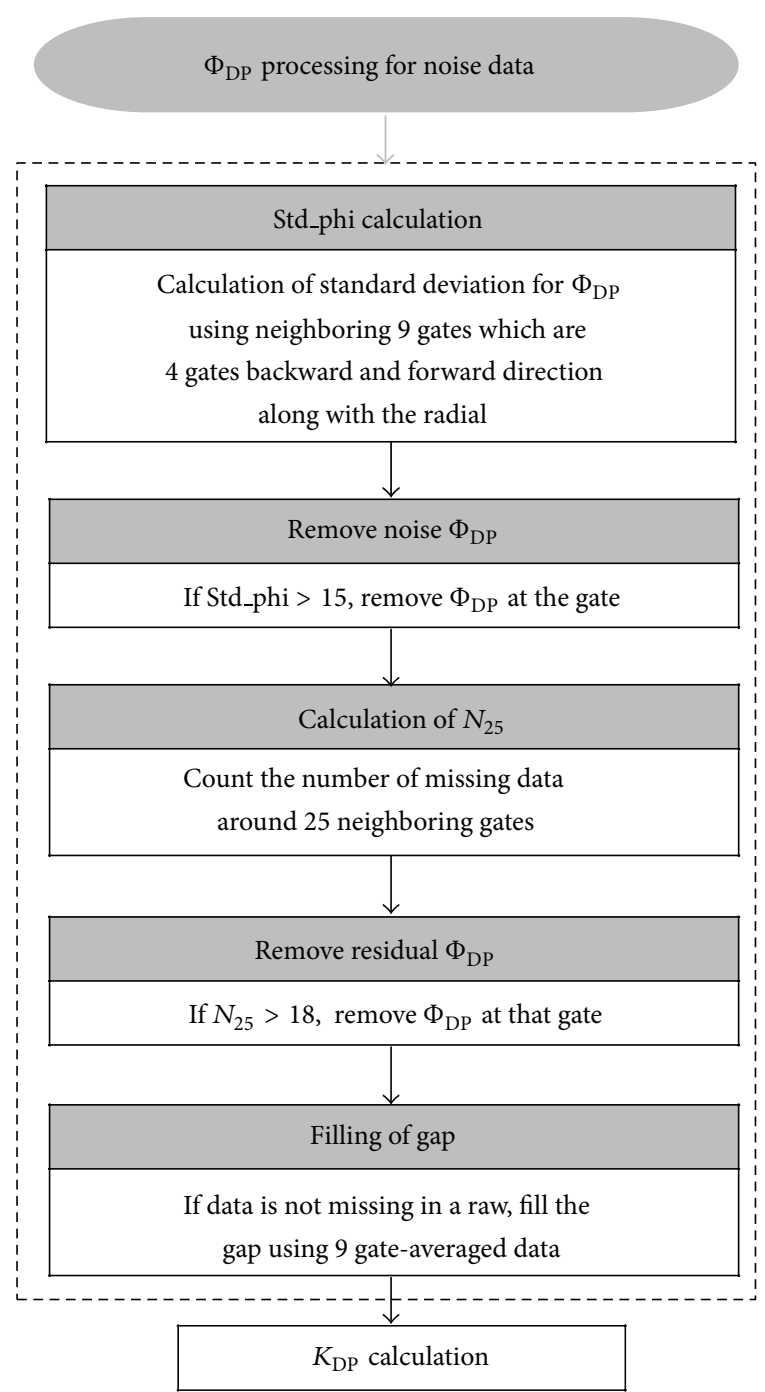

Figure 3: Noise removal flowchart for differential phase shift.

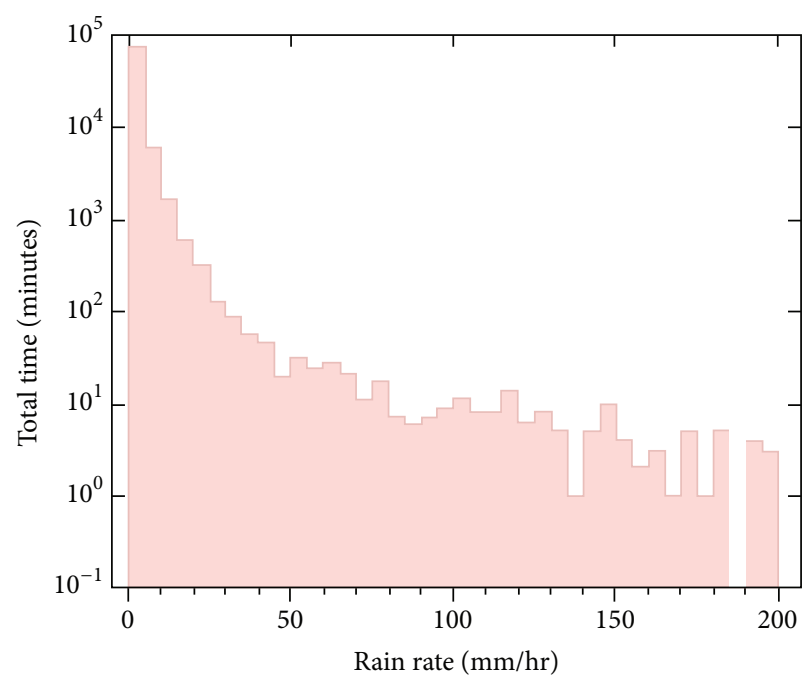

FIGURE 4: Histogram of rain rate calculated using 84,574 samples of 1 min DSD after quality control. 
TABLE 1: Rainfall cases and different source conditions used in the study.

\begin{tabular}{lcc}
\hline Items & Period & Sources \\
\hline Case 1 & 2011. 6.25.0000 LST 6. 26.1400 LST & Changma front and typhoon \\
Case 2 & 2011.7 .09 .0000 LST 7. 10.2200 LST & Changma front \\
Case 3 & 2011.8 .07 .1800 LST 8. 08.0300 LST & Typhoon \\
\hline
\end{tabular}

further by Mishchenko et al. [22]. The shape of a falling raindrop in air is determined by a balance of three types of forces working on the drop surface: hydrostatic pressure, surface tension, and aerodynamic pressure. To obtain the specific differential phase using DSDs, three raindrop shape assumptions are used, as described in Ryzhkov et al. [23]. The numerical model of Beard and Chuang [24], which agrees well with wind tunnel measurements, suggests that the equilibrium values of the raindrop axis ratio $r$ are related to the equivolume diameter in $\mathrm{mm}, D$ by

$$
\begin{aligned}
r= & 1.0048+0.500057 D-0.02628 D^{2} \\
& +0.003682 D^{3}-0.0001677 D^{4}
\end{aligned}
$$

(hereafter EQU). The actual shapes of raindrops in turbulent flow are expected to be different from the equilibrium shape due to drop oscillation. Oscillating drops appear to be more spherical on average than the drops with equilibrium shapes, as shown by Andsager et al. [25] in laboratory studies. They showed that the shape of raindrops between 1.1 and $4.4 \mathrm{~mm}$ is better explained by the following formula:

$$
r=1.012-0.01445 D-0.01028 D^{2} .
$$

Bringi et al. [26] [hereafter BRI] suggested using (2) for drops with sizes smaller than $4.4 \mathrm{~mm}$ and (1) for larger sizes. Another shape-diameter relation recently proposed by Brandes et al. [14] [hereafter BRA] combines the observations of different authors:

$$
\begin{aligned}
r= & 0.9951+0.025 D-0.03644 D^{2} \\
& +0.005303 D^{3}+0.0002492 D^{4} .
\end{aligned}
$$

Another parameter in the T-matrix calculations is the temperature, which is assumed to be $20^{\circ} \mathrm{C}$ in this study. It is also necessary to take the canting angle into consideration, because it can account for a $6 \%$ reduction in the coefficient of the $R\left(K_{\mathrm{DP}}\right)$ relation [27] and may give small negative biases in the estimators [28]. The distribution of canting angles of raindrops is Gaussian with a mean of $0^{\circ}$ and a standard deviation of $10^{\circ}$, and these values have been used commonly in previous studies $[27,29]$.

To validate each relationship, the normalized error (NE), fractional root mean square error (RMSE), and correlation coefficients (CC) are used:

$$
\mathrm{NE}=\frac{(1 / N) \sum_{i=1}^{N}\left(\left|R_{R, i}-R_{G, i}\right|\right)}{\overline{R_{G}}}
$$

$$
\begin{gathered}
\text { RMSE }=\left[\frac{1}{N} \sum_{i=1}^{N}\left(R_{R, i}-R_{G, i}\right)^{2}\right]^{1 / 2}, \\
\mathrm{CC}=\frac{\sum_{i=1}^{N}\left(R_{R, i}-\overline{R_{R}}\right)\left(R_{G, i}-\overline{R_{G}}\right)}{\left[\sum_{i=1}^{N}\left(R_{R, i}-\overline{R_{R}}\right)\right]^{1 / 2}\left[\sum_{i=1}^{N} R_{G, i}-\overline{R_{G}}\right]^{1 / 2}} .
\end{gathered}
$$

Here $N$ is the number of $R_{R}$ and $R_{G}$ pairs and $\overline{R_{R}}$ and $\overline{R_{G}}$ are the averaged rain rate for 1 hour for the radar and gage, respectively. The above measures are calculated using hourly rainfall amount for the radar and gage at the point. Negative $K_{\mathrm{DP}}$ is set to 0 in calculating $R\left(K_{\mathrm{DP}}\right)$. The point rainfall from radar was obtained by averaging rainfall over a small area $\left(500 \mathrm{~m} \times 1^{\circ}\right)$ centered on each rain gage.

\section{Results}

\subsection{Rainfall Case Studies and Quality Control of Differential Phase Shift}

3.1.1. Rainfall Distributions. In this study, three precipitation systems in 2011 were analyzed: one associated with the Changma front and a typhoon from 0000 LST on June 25 to 1400 LST on June 26, a second only with the Changma front from 0000 LST on July 9 to 2000 LST on July 10, and a third only with a typhoon from 2100 LST on August 7 to 0300 LST on August 8 (Table 1).

Figure 5 shows the time series of total rainfall amount observed by the ground rain gages in each case, obtained by summing the amount of rainfall observed by all the rain gages within the radius of the radar. In Case 1, there are two peaks of rainfall: the first due to the Changma front and the second to the typhoon. There are three peaks associated with the Changma front in Case 2. The third case was a precipitation system caused by the typhoon but of relatively short duration.

3.1.2. Quality Control of Differential Phase Shift. Differential phase shift is defined as the difference between the vertical and horizontal phases of the precipitation particles and is used to calculate $K_{\mathrm{DP}}$. If the processing of $\Phi_{\mathrm{DP}}$ is not successful, the calculation of $K_{\mathrm{DP}}$ and rainfall estimation is affected. The maximum observable value of $\Phi_{\mathrm{DP}}$ is 180 degrees for the Bislsan radar in 2011. If the real $\Phi_{\mathrm{DP}}$ exceeds this value in heavy rainfall, $\Phi_{\mathrm{DP}}$ may be folded and should be unfolded for quantitative use. There is also considerable noise in the observed $\Phi_{\mathrm{DP}}$ and this should be removed. Figure 6 shows the results of noise removal and unfolding of differential phase shift for observations on 1330 LST on June 26 and 0246 LST on August 8 in 2011, respectively.

Considerable noise was observed to the west of the radar center, and this has clearly been removed by the noise removal 


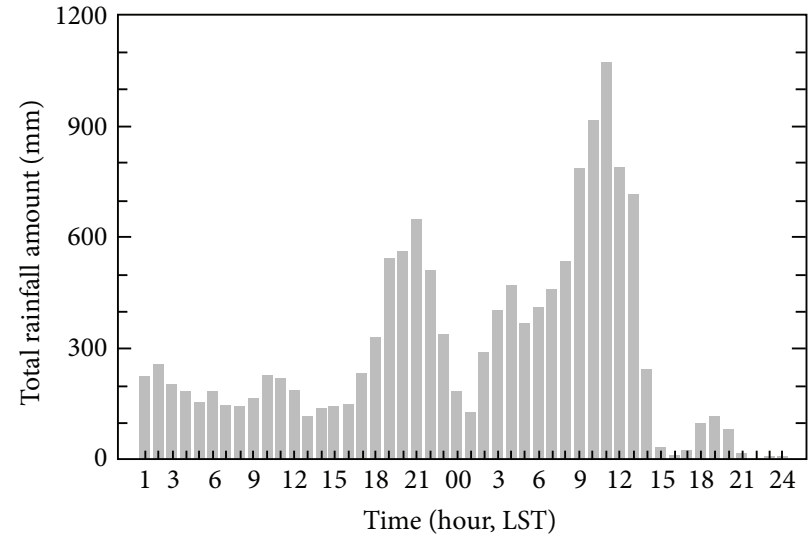

(a)

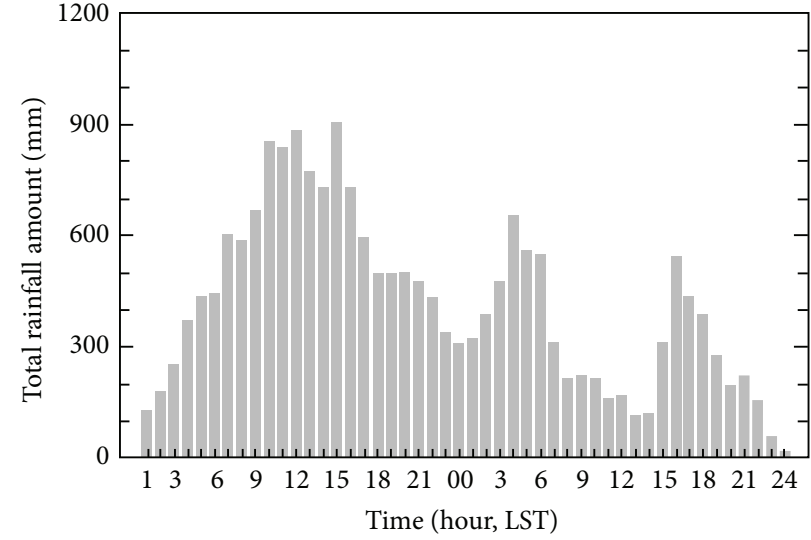

(b)

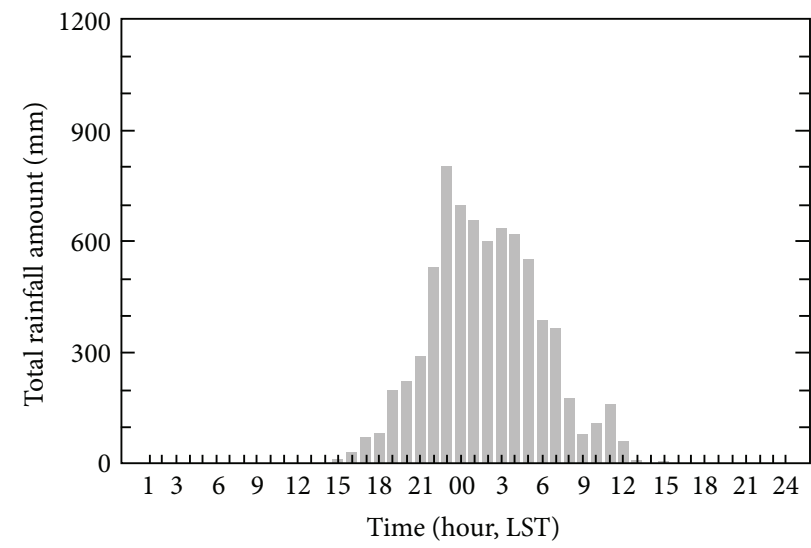

(c)

FIGURE 5: Time series of total rainfall amount, defined as rainfall summed over all rain gages within the radar coverage for (a) Case 1, (b) Case 2, and (c) Case 3.

algorithm (Figures 6(a) and 6(b)). Folding of $\Phi_{\mathrm{DP}}$ occurs at a distance of $60 \mathrm{~km}$ south of the center of the radar coverage; the algorithm successfully recovers $\Phi_{\mathrm{DP}}$ (Figures $6(\mathrm{c})$ and 6(d)). It is necessary to apply the noise removal algorithm after unfolding so that it does not remove the unfolding region, which is an area of real echo. Folding of the differential phase shift occurred from 0215 LST on August 8 in Case 3 and all events were successfully unfolded (not shown here).

3.2. $R\left(K_{D P}\right)$ Relations and Validation. Relations between rain rate and $K_{\mathrm{DP}}, R\left(K_{\mathrm{DP}}\right)$, were determined using a standard weighted least square polynomial fit. $K_{\mathrm{DP}}$ and rain rate were calculated using the observed DSDs from 84,574 samples.

Equations (7), (8), and (9) were obtained by assuming EQU, BRI, and BRA drop shapes, respectively. Their correlation coefficients were $0.87,0.86$, and 0.84 , respectively. The $R\left(K_{\mathrm{DP}}\right)$ BSC referred to below is the $R\left(K_{\mathrm{DP}}\right)$ calculated from DSD data observed at Busan in Korea:

$$
\begin{aligned}
& R=50.9 K_{\mathrm{DP}}^{0.827} \\
& R=61.4 K_{\mathrm{DP}}^{0.833} \\
& R=53.4 K_{\mathrm{DP}}^{0.787} .
\end{aligned}
$$

TABLE 2: List of different relations used for validation.

\begin{tabular}{lcl}
\hline Number & \multicolumn{1}{c}{ Relationship } & Drop shape \\
\hline 1 & $R=3.64 \times 10^{-2} Z^{0.625}$ & $\begin{array}{l}\text { Marshall Palmer } \\
\text { Measured DSDs at Oklahoma, } \\
\text { EQU shape } \\
3\end{array}$ \\
$R=44.0 K_{\mathrm{DP}}^{0.822}$ & $R=50.3 K_{\mathrm{DP}}^{0.812}$ & $\begin{array}{l}\text { Measured DSDs at Oklahoma, } \\
\text { BRI shape } \\
\text { Measured DSDs at Oklahoma, } \\
\text { BRA shape }\end{array}$ \\
5 & $R=47.3 K_{\mathrm{DP}}^{0.791}$ & $\begin{array}{l}\text { Measured DSDs at Busan, EQU } \\
\text { shape } \\
6\end{array}$ \\
$R$ & $R=50.9 K_{\mathrm{DP}}^{0.827}$ \\
7 & $R=51.4 K_{\mathrm{DP}}^{0.833}$ & $\begin{array}{l}\text { Measured DSDs at Busan, BRI } \\
\text { shape } \\
\text { Measured DSDs at Busan, BRA } \\
\text { shape }\end{array}$ \\
\hline
\end{tabular}

The accuracies of these relationships were compared with those of the $R\left(K_{\mathrm{DP}}\right)$ based on DSDs observed in Oklahoma City (hereafter $R\left(K_{\mathrm{DP}}\right)$ OKC) [30] and $R=200 R^{1.6}$ (Table 2). Only the times for which gages have rainfall greater than $0.1 \mathrm{~mm}$ were selected, and there are 2,891, 3051, and 423 pairs for Cases 1-3, respectively. 
Differential phase shift (deg.) 2011/06/26 13:30:51 KST EL: 0.46

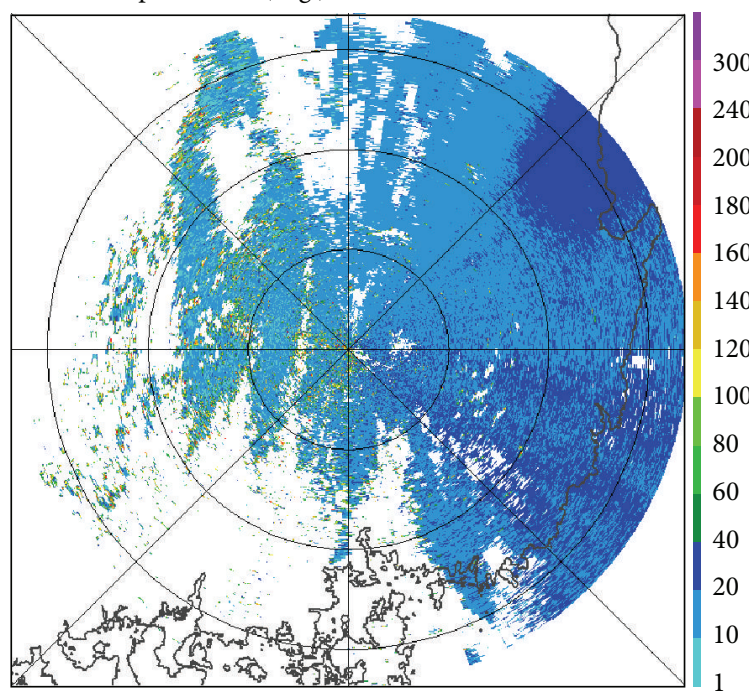

BSL range: $101 \mathrm{~km}$ Bin size: $0.125 \mathrm{~km}$ Bins: 813 Sweep rate: 18.0 (deg/s)

(a)

Differential phase shift (deg.) 2011/08/08 2:46:4 KST EL: 0.50

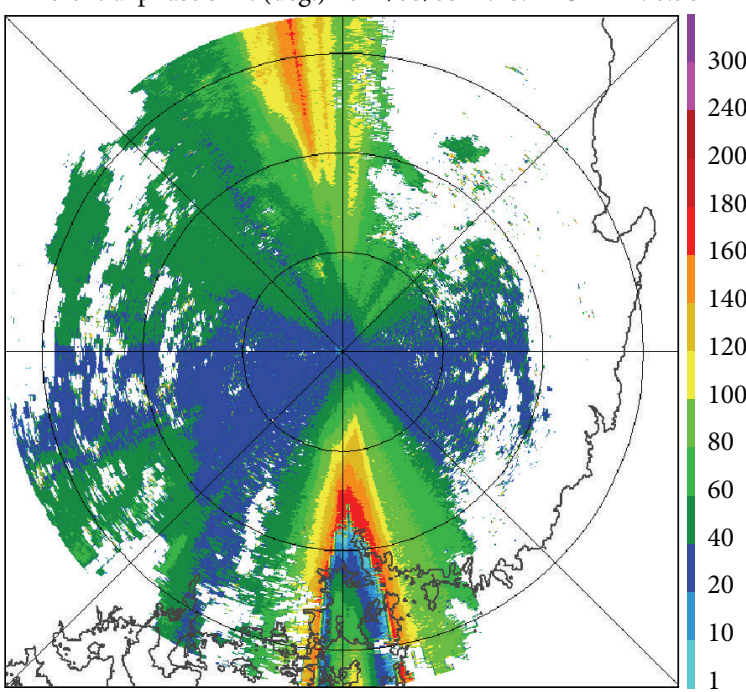

BSL range: $101 \mathrm{~km}$ Bin size: 0.125 km Bins: 813 Sweep rate: 18.0 (deg/s)

(c)
Differential phase shift (deg.) QCD 2011/06/26 13:30:51 KST EL: 0.46

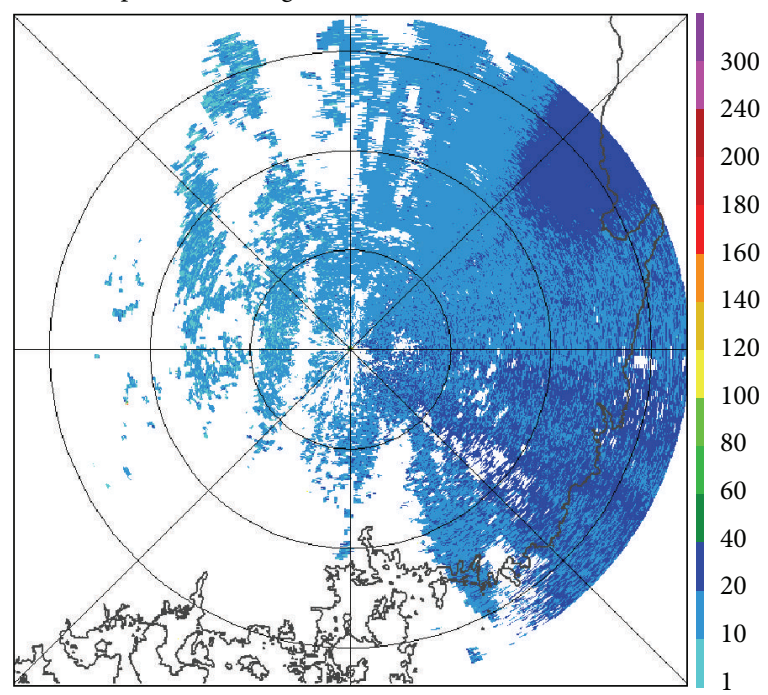

BSL range: $101 \mathrm{~km}$ Bin size: $0.125 \mathrm{~km}$ Bins: 813 Sweep rate: 18.0 (deg/s)

(b)

Differential phase shift (deg.) QCD 2011/08/08 2:46:4 KST EL: 0.50

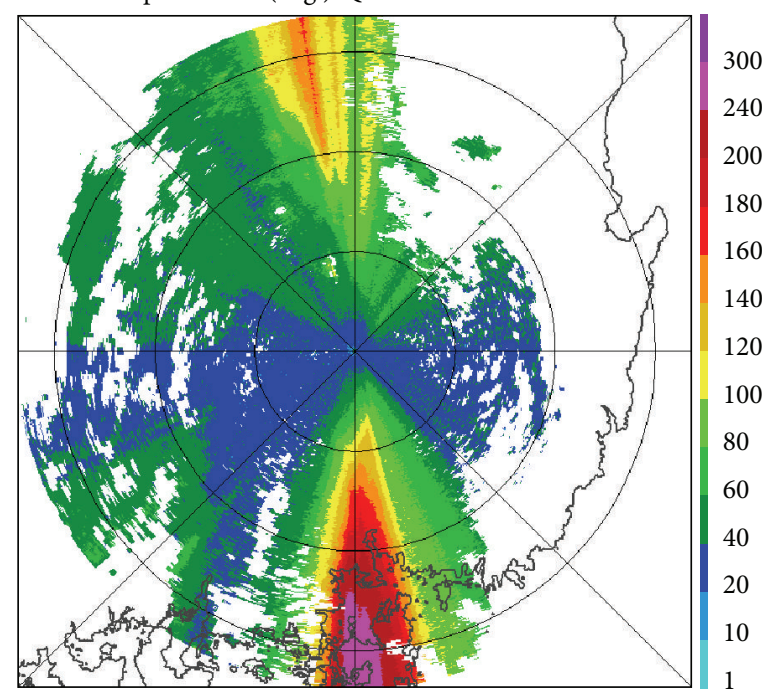

BSL range: $101 \mathrm{~km}$ Bin size: $0.125 \mathrm{~km}$ Bins: 813 Sweep rate: $18.0(\mathrm{deg} / \mathrm{s})$

(d)

FIGURE 6: The results of noise removal and unfolding of differential phase shift. (a) Raw $\Phi_{\text {DP }}$ observed at 1330 LST on June 26, 2011, before noise removal and (b) after noise removal. (c) Raw $\Phi_{\mathrm{DP}}$ observed at 0246 LST on August 8, 2011, before unfolding and (d) after unfolding.

Figure 7 shows scatterplots of gage rainfall against radar rainfall obtained from the Marshall Palmer (MP) $R(Z)$, $R\left(K_{\mathrm{DP}}\right) \mathrm{OKC}$, and $R\left(K_{\mathrm{DP}}\right)$ BSC.

Blue triangles are for equilibrium drop shape, red circles for the Brandes drop shape, and black crosses for the Bringi drop shape. In Case 1 the statistics of the radar rainfall determined from $R(Z)$ were $\mathrm{NE}=0.54$, RMSE $=4.3 \mathrm{~mm}$, and $\mathrm{CC}=0.82$. Regardless of the drop shape, the statistics for rainfall obtained by $R\left(K_{\mathrm{DP}}\right) \mathrm{OKC}$ and $\mathrm{BSC}$ were similar. Better values of CC and NE were obtained with $R(Z)$ than with $R\left(K_{\mathrm{DP}}\right)$, but the RMSE of $R\left(K_{\mathrm{DP}}\right)$ was a little better than that of $R(Z)$. Case 2 shows a similar pattern to Case 1 , but the RMSE of the $R\left(K_{\mathrm{DP}}\right)$ with EQU drop shape was good in $R\left(K_{\mathrm{DP}}\right)$ BSC. In Case 3, $R(Z)$ showed good results in all statistics and the RMSE of $R\left(K_{\mathrm{DP}}\right)$ BSC was lower than that of $R\left(K_{\mathrm{DP}}\right) \mathrm{OKC}$. The quality control algorithm for differential phase shift has resulted in much better results for $R\left(K_{\mathrm{DP}}\right)$ than in the previous study [19].

$K_{\mathrm{DP}}$ is susceptible to fluctuations of DSD and is noisy in light precipitation. In all cases used in this study, there is a large proportion of light precipitation, and the performance of the $R\left(K_{\mathrm{DP}}\right)$ is either no better or worse than the performance of $R(Z)$. Therefore, only samples with gage rainfall intensity greater than $10 \mathrm{~mm} \mathrm{~h}^{-1}$ in all cases were selected and analyzed. The number of samples with heavier rainfall was 1,072 . 


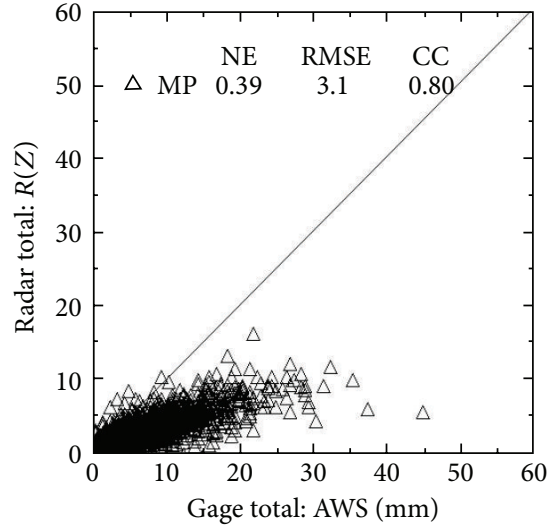

(a)

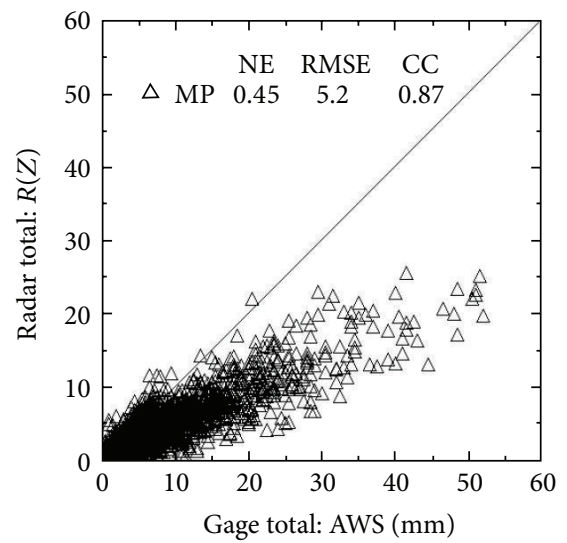

(d)

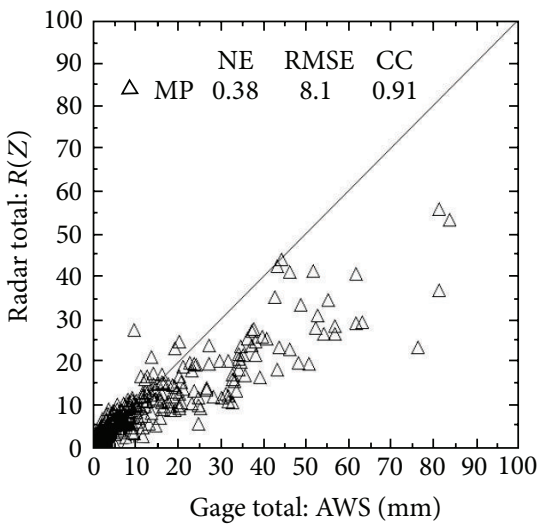

(g)

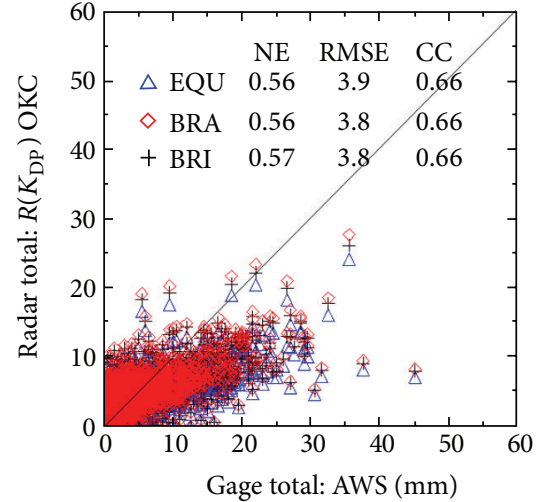

(b)

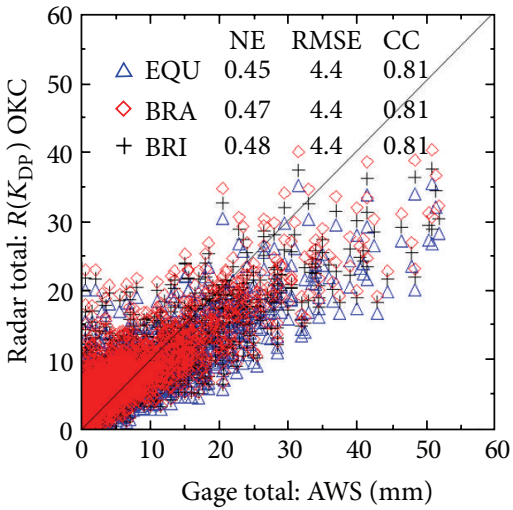

(e)

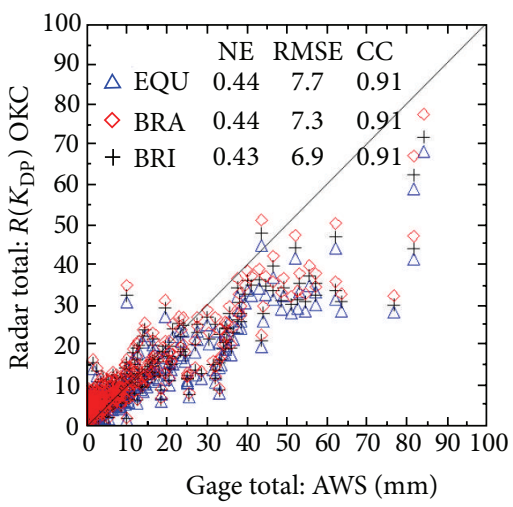

(h)

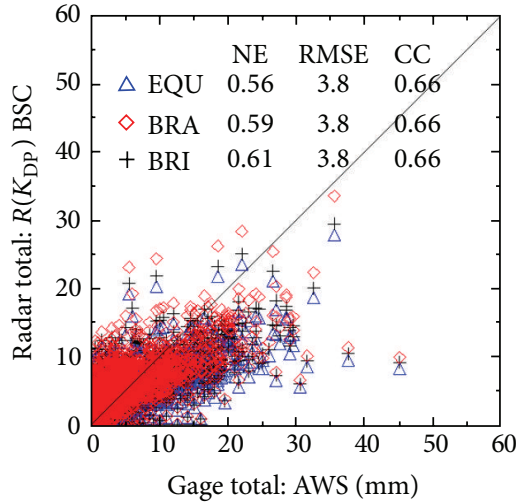

(c)

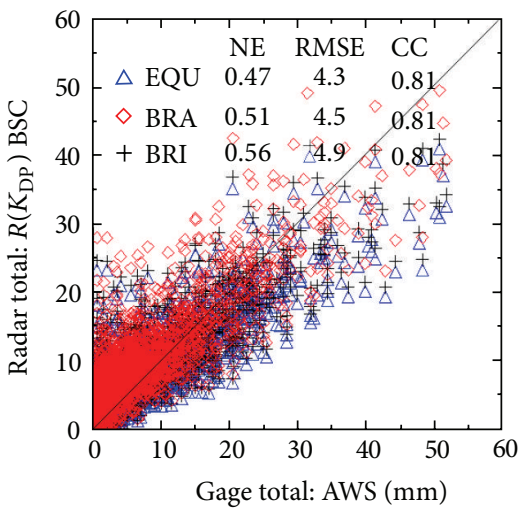

(f)

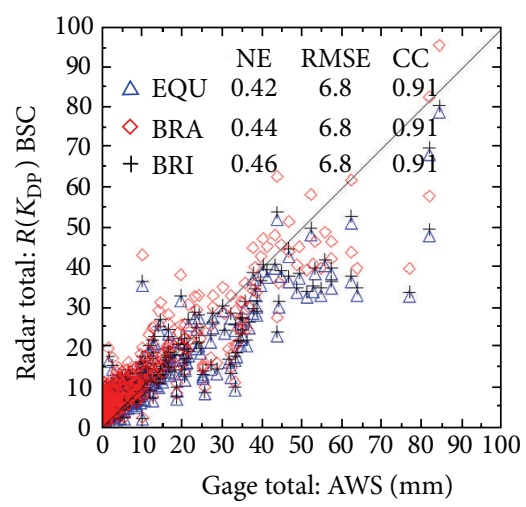

(i)

FIGURE 7: Scatterplots of gage rainfall against radar rainfall estimated by the $\mathrm{MP} R(Z), R\left(K_{\mathrm{DP}}\right)$ OKC, and $R\left(K_{\mathrm{DP}}\right)$ BSC relations for Cases $1-3$. (a), (b), and (c) are for Case 1; (d), (e), and (f) are for Case 2; and (g), (h), and (i) are for Case 3. Blue triangles are for equilibrium drop shape, red diamond for the Brandes drop shape, and black crosses for the Bringi drop shape.

Values of RMSE increase when only heavy rain samples are selected. With the exception of the CC, the results of $R\left(K_{\mathrm{DP}}\right)$ are greatly improved compared with $R(Z)$. The results of $R\left(K_{\mathrm{DP}}\right)$ BSC are better than those of $R\left(K_{\mathrm{DP}}\right)$ OKC, with the $\mathrm{BRI}$ shape performing the best, giving $\mathrm{NE}=0.27$, and RMSE $=6.7$ (Table 3$)$.

3.3. Discussion. For rainfall heavier than $10 \mathrm{~mm} \mathrm{~h}^{-1}, R\left(K_{\mathrm{DP}}\right)$ BSC BRI was most accurate but its normalized error is still
$27 \%$. There could be many sources of error, but the differing accuracy of the different rainfall relations was first examined by using the tropical $R(Z)$ relation used in next generation radar (NEXRAD) in USA:

$$
R=1.21 \times 10^{-2} Z^{0.833} .
$$

Figure 8 shows the comparison of gage and radar rainfall estimated for the NEXRAD $R(Z)$ relation. In Case 1 where rainfall was caused by the Changma front and typhoon, 


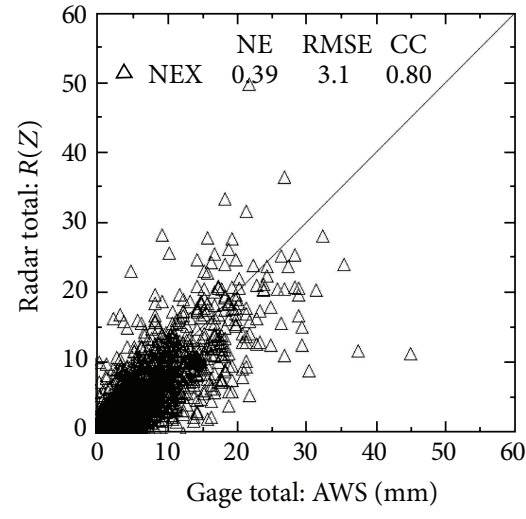

(a)

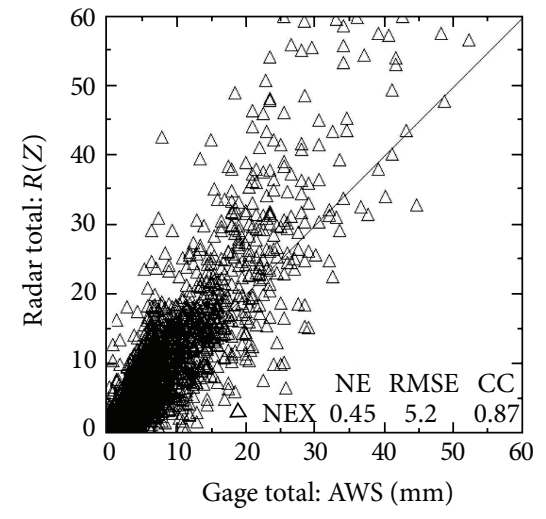

(b)

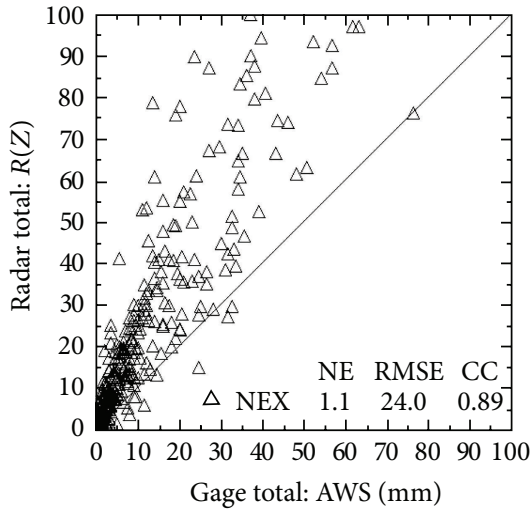

(c)

FIGURE 8: Scatterplots of gage rainfall against radar rainfall obtained using the tropical $R(Z)$ relation derived from the US NEXRAD network for (a) Case 1, (b) Case 2, and (c) Case 3.

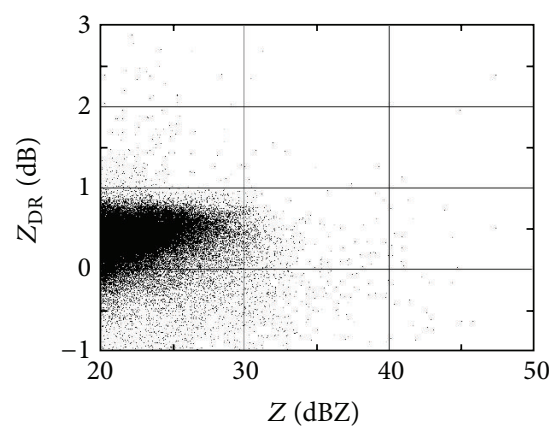

(a)

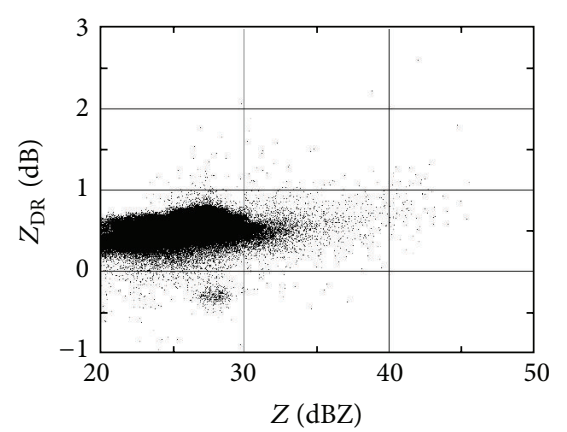

(b)

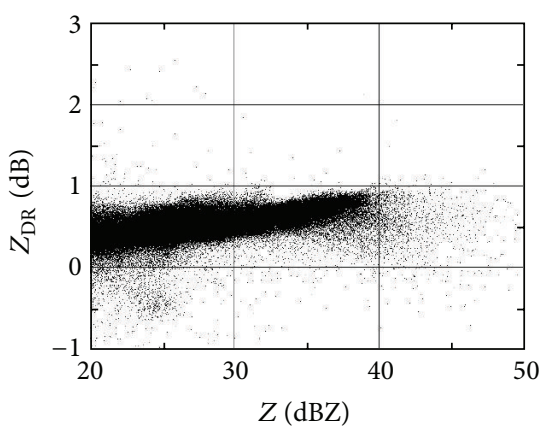

(c)

FIGURE 9: Scatterplots of average $Z$ against $Z_{\mathrm{DR}}$ for (a) Case 1, (b) Case 2, and (c) Case 3.

TABLE 3: Rainfall statistics for the different relations for high rainfall rate conditions for all three cases combined.

\begin{tabular}{lcccc}
\hline Number & Relation & NE & RMSE & CC \\
\hline 1 & $R=3.64 \times 10^{-2} Z^{0.625}$ & 0.52 & 11.5 & 0.78 \\
2 & $R=44.0 K_{\mathrm{DP}} 0.822$ & 0.39 & 9.2 & 0.78 \\
3 & $R=50.3 K_{\mathrm{DP}} 0.812$ & 0.32 & 8.0 & 0.78 \\
4 & $R=47.3 K_{\mathrm{DP}} 0.791$ & 0.34 & 8.4 & 0.77 \\
5 & $R=50.9 K_{\mathrm{DP}} 0.827$ & 0.33 & 8.0 & 0.78 \\
6 & $R=61.4 K_{\mathrm{DP}} 0.833$ & 0.27 & 6.7 & 0.78 \\
7 & $R=53.4 K_{\mathrm{DP}} 0.787$ & 0.29 & 7.4 & 0.78 \\
\hline
\end{tabular}

$\mathrm{NE}=0.39, \mathrm{RMSE}=3.1$, and $\mathrm{CC}=0.8$, and its performance is much better than that of $R\left(K_{\mathrm{DP}}\right)$. In the other two cases with either only the Changma front or only the typhoon, the radar rainfall was not in good agreement with the gage. This was particularly so in Case 3 , with RMSE $=24.0 \mathrm{~mm} \mathrm{~h}^{-1}$ even though it was typhoon rainfall. The difference in accuracy with each rainfall case was greater than that of $R\left(K_{\mathrm{DP}}\right)$. It is believed that $K_{\mathrm{DP}}$ is less sensitive to the DSD variation associated with different precipitation types than is the reflectivity.

Secondly, average $Z$ and $Z_{\mathrm{DR}}$ were calculated for the rainfall periods in each case (Figure 9). Small raindrops with
$Z_{\mathrm{DR}}$ less than $1 \mathrm{~dB}$ were dominant in all cases, but there were significant differences in the reflectivity. The $Z-Z_{\mathrm{DR}}$ scattering distribution is also different from the general one in which $Z_{\mathrm{DR}}$ increases with $Z$, and this would affect the accuracy of $R\left(K_{\mathrm{DP}}\right)$. Accordingly, it may be necessary to calculate the $R\left(K_{\mathrm{DP}}\right)$ only for rainfall caused by the typhoon.

\section{Summary and Conclusions}

Within several years, polarimetric radars will be the main tools to monitor and forecast severe weather and flash flooding in Korea. To assess the performance of rainfall estimation using specific differential phase observed from the Bislsan radar, the first polarimetric radar installed in Korea, three rainfall cases were selected for 2011. These were associated with different conditions: the Changma front and typhoon, only the Changma front, and only a typhoon.

For quantitative use of $K_{\mathrm{DP}}$, a data quality algorithm for differential phase shift was developed. The algorithm is composed of two steps: the unfolding of $\Phi_{\mathrm{DP}}$ and the removal of scattered noise. This order is important to ensure that areas of folded $\Phi_{\mathrm{DP}}$, which are part of the real meteorological target, are not removed as noise. All noise was removed and folded $\Phi_{\mathrm{DP}}$ were unfolded. This algorithm is essential for the use of $K_{\mathrm{DP}}$ for many applications such as 
rainfall estimation, hydrometeor classification, and numerical modeling.

The $R\left(K_{\mathrm{DP}}\right)$ relations for S-band polarimetric radar were calculated using 84,754 samples of observed DSD data with three different drop shape assumptions: equilibrium shape, the Brandes drop shape, and the Bringi drop shape. To assess the performance of these relationships, we compared them with the results of the MP $R(Z)$ relation and $R\left(K_{\mathrm{DP}}\right)$ obtained at Oklahoma in the USA.

For Case 1 (the rainfall caused by the Changma front and typhoon) the values of NE, RMSE, and CC for radar rainfall determined by $R(Z)$ were $0.54 \mathrm{~mm}, 4.3 \mathrm{~mm}$, and $0.82 \mathrm{~mm}$, respectively. Rainfall obtained using the $R\left(K_{\mathrm{DP}}\right)$ OKC and BSC had similar statistics, regardless of the drop shape. Values of CC and NE determined by $R(Z)$ were better than those for $R\left(K_{\mathrm{DP}}\right)$, but the RMSE of $R\left(K_{\mathrm{DP}}\right)$ was slightly better. Case 2 showed a similar pattern to Case 1 , but the RMSE of $R\left(K_{\mathrm{DP}}\right)$ with EQU drop shape was the best of the $R\left(K_{\mathrm{DP}}\right)$ BSC. In Case $3, R(Z)$ showed good results in all statistics and the RMSE of $R\left(K_{\mathrm{DP}}\right)$ BSC showed better performance than that of $R\left(K_{\mathrm{DP}}\right)$ OKC.

To compare the performance of each relation for heavier rainfall, the gage rainfall samples with intensity greater than $10 \mathrm{~mm} \mathrm{~h}^{-1}$ in all cases were selected and analyzed. With the exception of the CC, the results of $R\left(K_{\mathrm{DP}}\right)$ improved considerably compared with those of $R(Z)$. The $R\left(K_{\mathrm{DP}}\right)$ BSC gave better results than the $R\left(K_{\mathrm{DP}}\right)$ OKC. Of the results from $R\left(K_{\mathrm{DP}}\right) \mathrm{BSC}$, the relation using the BRI drop shape showed the best statistics, with $\mathrm{NE}=0.27$ and $\mathrm{RMSE}=6.7 \mathrm{~mm}$.

Finally, quality control of differential phase shift is essential to obtain reliable $K_{\mathrm{DP}}$, which is an important polarimetric variable for many purposes. The relation $R\left(K_{\mathrm{DP}}\right)$ should be calculated using a DSD that reflects the characteristics of the region. Further, since the accuracy of rainfall estimation is affected by the drop shape assumption, this assumption should be considered in developing an optimal rainfall estimation algorithm using other polarimetric variables. Although further research is required, the results of this study are expected to contribute to various fields such as hydrometeor classification and to improve the operational accuracy of rainfall estimation from polarimetric radar in Korea.

\section{Conflict of Interests}

The authors declare that they have no conflict of interests regarding the publication of this paper.

\section{Acknowledgments}

The authors acknowledge the provision of radar data and AWS data for this work by the Ministry of Land, Transportation and the Korea Meteorological Administration. The authors also acknowledge the code for simulating scattering provided by Professor V. N. Bringi at Colorado State University. This research was supported by the National Research Foundation of Korea (NRF) through a Grant provided by the Korean Ministry of Education, Science \& Technology (MEST) in 2014 (no. K200603874). This work was also funded by the Korea Meteorological Administration Research and Development Program under Grant CATER 2012-2071 and JST/CREST.

\section{References}

[1] E. Campos and I. Zawadzki, "Instrumental uncertainties in ZR relations," Journal of Applied Meteorology, vol. 39, no. 7, pp. 1088-1102, 2000.

[2] C.-H. You, D.-I. Lee, S.-M. Jang et al., "Characteristics of rainfall systems accompanied with Changma front at Chujado in Korea," Asia-Pacific Journal of Atmospheric Sciences, vol. 46, no. 1, pp. 41-51, 2010.

[3] J. W. Wilson and E. A. Brandes, "Radar measurement of rainfall-a summary," Bulletin of the American Meteorological Society, vol. 60, no. 9, pp. 1048-1058, 1979.

[4] P. M. Austin, "Relations between measured radar reflectivity and surface rainfall," Monthly Weather Review, vol. 115, no. 5, pp. 1053-1070, 1987.

[5] C. You, D. Lee, M. Jang, K. Seo, K. Kim, and B. Kim, "The characteristics of rain drop size distributions using a POSS in Busan area," Journal of the Korean Meteorological Society, vol. 40, no. 6, pp. 713-724, 2004.

[6] M. Jang, D. Lee, and C. You, "Z-R relationship and DSD analyses using a POSS disdrometer-part I: precipitation cases in Busan," Journal of the Korean Meteorological Society, vol. 40, pp. 557570, 2004.

[7] M. Suk, K. Nam, Y. Kim, and S. Oh, "Estimation of quantitative rain intensity from radar reflectivities using a wind probability matching method," Journal of the Korean Meteorological Society, vol. 41, pp. 123-138, 2005.

[8] J. Vivekanandan, D. S. Zrnic, S. M. Ellis, R. Oye, A. V. Ryzhkov, and J. Straka, "Cloud microphysics retrieval using S-band dualpolarization radar measurements," Bulletin of the American Meteorological Society, vol. 80, no. 3, pp. 381-388, 1999.

[9] A. V. Ryzhkov and D. S. Zrnic, "Discrimination between rain and snow with a polarimetric radar," Journal of Applied Meteorology, vol. 37, no. 10, pp. 1228-1240, 1998.

[10] S. E. Giangrande and A. V. Ryzhkov, "Estimation of rainfall based on the results of polarimetric echo classification," Journal of Applied Meteorology and Climatology, vol. 47, no. 9, pp. 24452462, 2008.

[11] A. V. Ryzhkov and D. S. Zrnic, "Assessment of rainfall measurement that uses specific differential phase," Journal of Applied Meteorology, vol. 35, no. 11, pp. 2080-2090, 1996.

[12] P. T. May, T. D. Keenan, D. S. Zrnić, L. D. Carey, and S. A. Rutledge, "Polarimetric radar measurements of tropical rain at a 5-cm wavelength," Journal of Applied Meteorology, vol. 38, no. 6, pp. 750-765, 1999.

[13] V. N. Bringi and V. Chandrasekar, The Polarimetric Basis for Characterizing Precipitation. Polarimetric Doppler Weather Radar: Principles and Applications, Cambridge University Press, Cambridge, UK, 2001.

[14] E. A. Brandes, G. Zhang, and J. Vivekanandan, "Experiments in rainfall estimation with a polarimetric radar in a subtropical environment," Journal of Applied Meteorology, vol. 41, pp. 674685, 2002.

[15] A. V. Ryzhkov, T. J. Schuur, D. W. Burgess, P. L. Heinselman, S. E. Giangrande, and D. S. Zrnic, "The joint polarization experiment: polarimetric rainfall measurements and hydrometeor 
classification," Bulletin of the American Meteorological Society, vol. 86, no. 6, pp. 809-824, 2005.

[16] R. Cifelli, V. Chandrasekar, S. Lim, P. C. Kennedy, Y. Wang, and S. A. Rutledge, "A new dual-polarization radar rainfall algorithm: application in Colorado precipitation events," Journal of Atmospheric and Oceanic Technology, vol. 28, no. 3, pp. 352-364, 2011.

[17] N. Balakrishnan and D. S. Zrnic, "Estimation of rain and hail rates in mixed-phase precipitation," Journal of the Atmospheric Sciences, vol. 47, no. 5, pp. 565-583, 1990.

[18] K. Aydin, V. N. Bringi, and L. Liu, "Rain-rate estimation in the presence of hail using S-band specific differential phase and other radar parameters," Journal of Applied Meteorology, vol. 34, no. 2, pp. 404-410, 1995.

[19] C. You, M. Kang, D. Lee, and H. Uyeda, "Rainfall estimation by S-band polarimetricradar in Korea-part I: preprocessing and preliminary results," Meteorological Applications. In press.

[20] B. E. Sheppard, "The measurement of raindrop size distributions using a small Doppler radar," Journal of Atmospheric and Oceanic Technology, vol. 7, pp. 255-268, 1990.

[21] P. C. Waterman, "Symmetry, unitarity, and geometry in electromagnetic scattering," Physical Review D, vol. 3, no. 4, pp. 825839, 1971.

[22] M. I. Mishchenko, L. D. Travis, and D. W. Mackowski, “T-matrix computations of light scattering by nonspherical particles: a review," Journal of Quantitative Spectroscopy and Radiative Transfer, vol. 55, no. 5, pp. 535-575, 1996.

[23] A. V. Ryzhkov, S. E. Giangrande, V. M. Melnikov, and T. J. Schuur, "Calibration issues of dual-polarization radar measurements," Journal of Atmospheric and Oceanic Technology, vol. 22, no. 8, pp. 1138-1155, 2005.

[24] K. V. Beard and C. C. Chuang, "A new model for the equilibrium shape of raindrops," Journal of the Atmospheric Sciences, vol. 44, pp. 1509-1524, 1987.

[25] K. Andsager, K. V. Beard, and N. F. Laird, "Laboratory measurements of axis ratios for large raindrops," Journal of the Atmospheric Sciences, vol. 56, no. 15, pp. 2673-2683, 1999.

[26] V. N. Bringi, V. Chandrasekar, J. Hubbert, E. Gorgucci, W. L. Randeu, and M. Schoenhuber, "Raindrop size distribution in different climatic regimes from disdrometer and dual-polarized radar analysis," Journal of the Atmospheric Sciences, vol. 60, no. 2, pp. 354-365, 2003.

[27] A. V. Ryzhkov, D. S. Zrnic, J. C. Hubbert, V. N. Bringi, J. Vivekanandan, and E. A. Brandes, "Polarimetric radar observations and interpretation of co-cross-polar correlation coefficients," Journal of Atmospheric and Oceanic Technology, vol. 19, no. 3, pp. 340-354, 2002.

[28] S. Y. Matrosov, K. A. Clark, B. E. Martner, and A. Tokay, "X-band polarimetric radar measurements of rainfall," Journal of Applied Meteorology, vol. 41, no. 9, pp. 941-952, 2002.

[29] T. D. Keenan, D. S. Zrnic, L. Carey, and P. May, "Sensitivity of $5-\mathrm{cm}$ wavelength polarimetric radar variables to raindrop axial ratio and drop size distributions," Journal of Applied Meteorology, vol. 40, pp. 526-545, 2001.

[30] A. V. Ryzhkov, S. E. Giangrande, and T. J. Schuur, "Rainfall estimation with a polarimetric prototype of WSR-88D," Journal of Applied Meteorology, vol. 44, no. 4, pp. 502-515, 2005. 

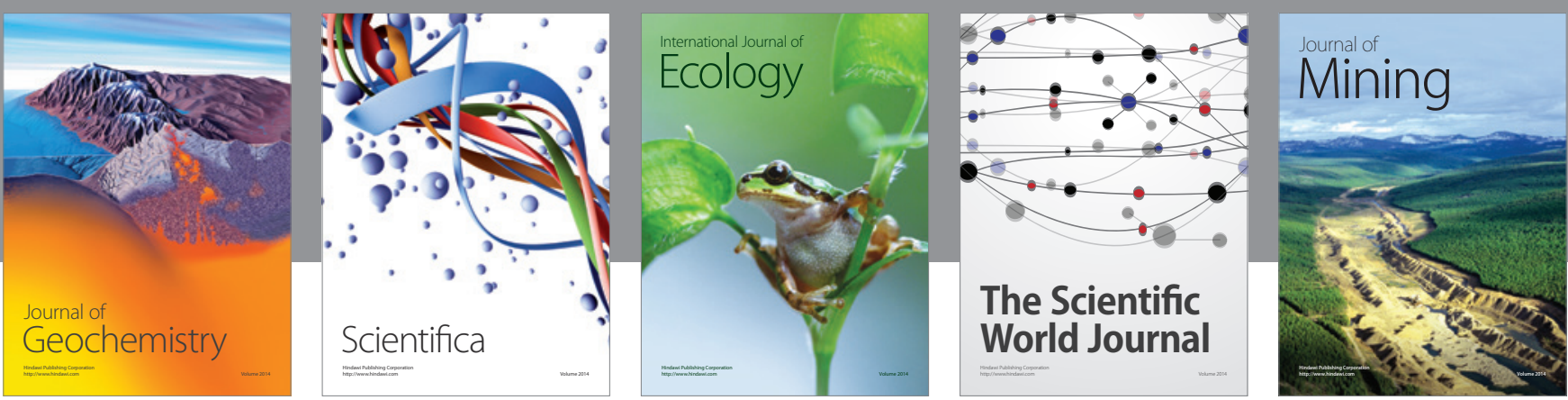

The Scientific World Journal
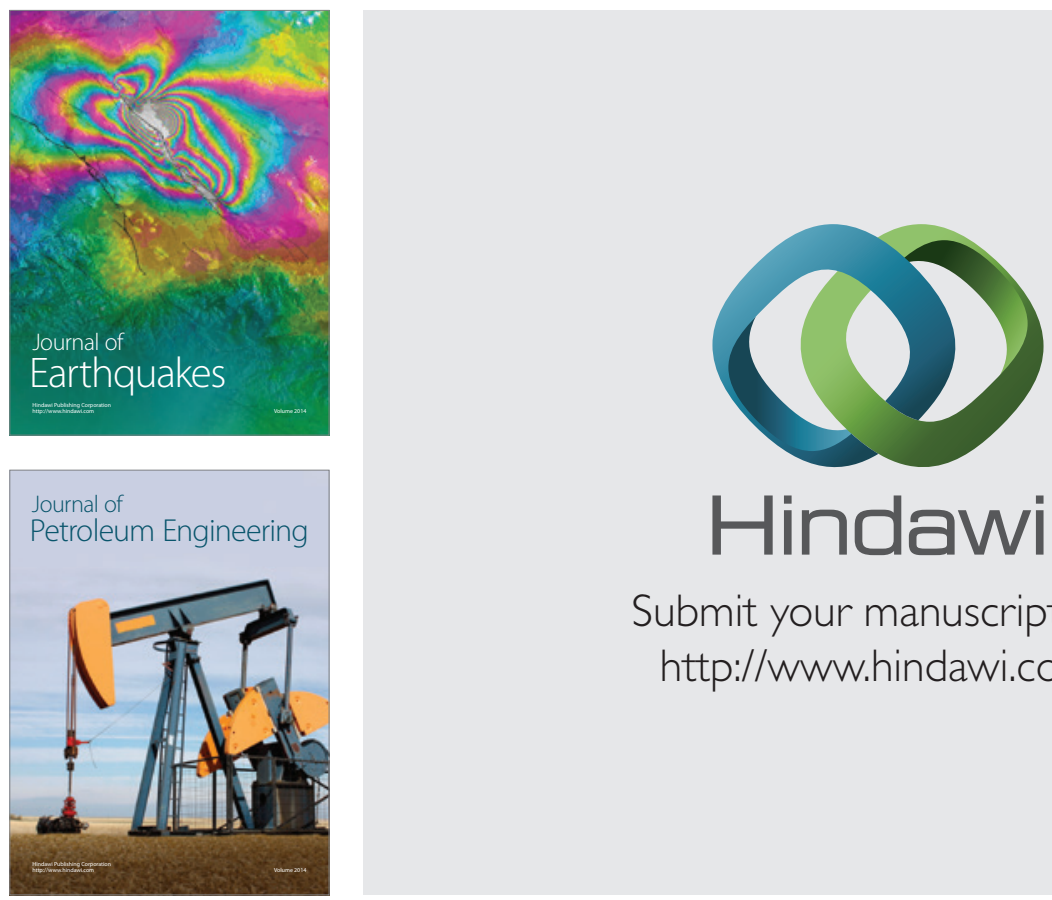

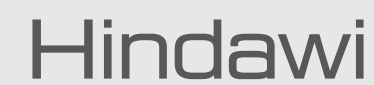

Submit your manuscripts at

http://www.hindawi.com
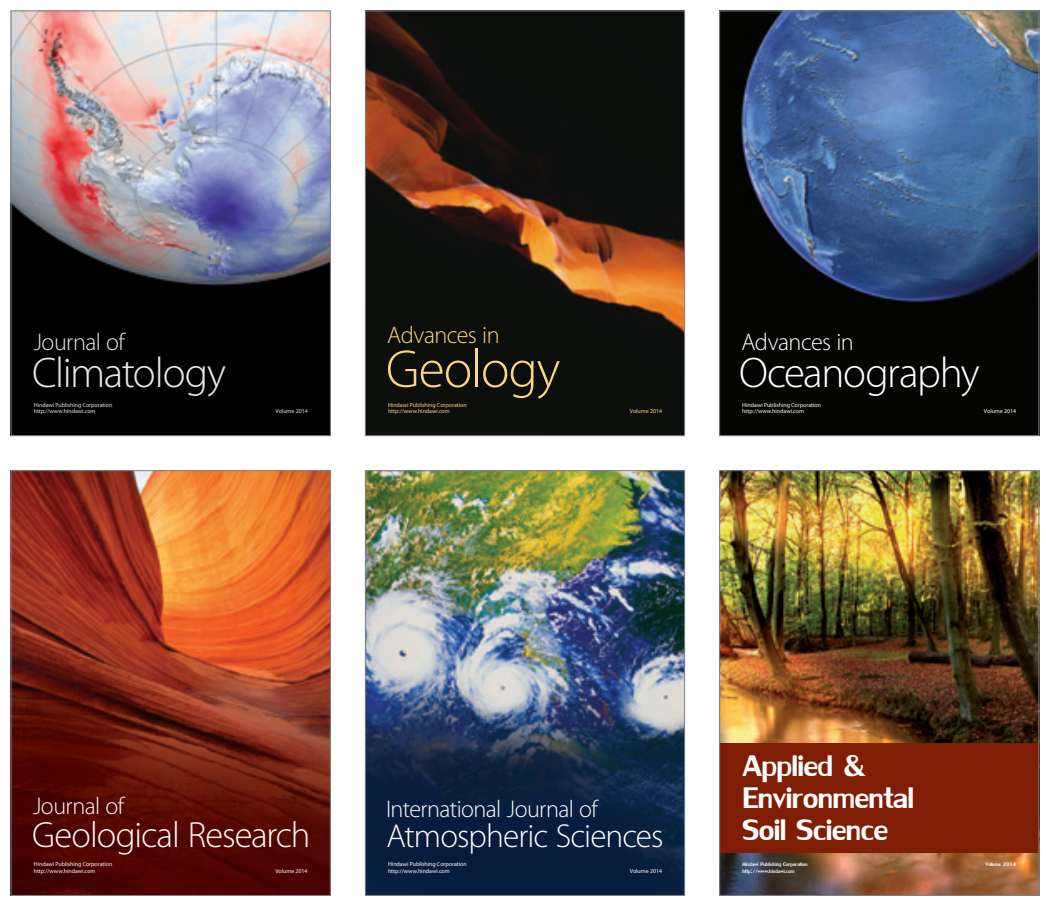
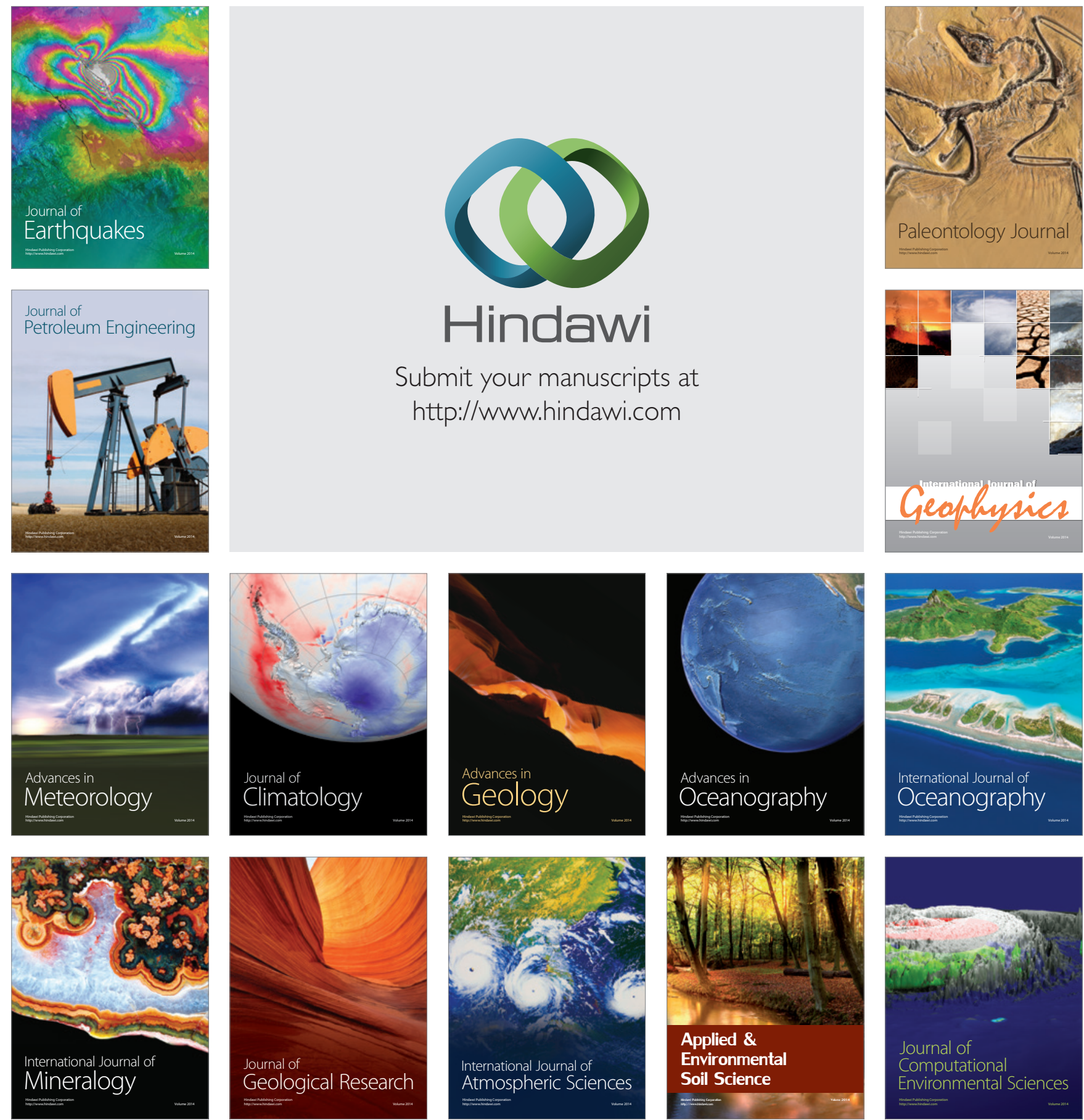